\title{
A literatura feminista de Nísia Floresta na formação em administração
}

\author{
Susane Petinelli Souza
}

\section{RESUMO}

Nísia Floresta é reconhecida como a primeira mulher brasileira a escrever sobre os ideais de igualdade desde 1830, e seu trabalho ajudou a constituir o pensamento do século XIX. Em uma época na qual a maioria das mulheres não tinha acesso à educação, essa latino-americana colocou em evidência a invisibilidade feminina. O objetivo do estudo é analisar o uso da literatura feminista de Nísia na formação de administradores. Para isso, realizou-se uma pesquisa bibliográfica sobre a literatura produzida pela escritora. Além disso, foram estabelecidos o contexto sócio-histórico da produção de sua obra e a relação do seu trabalho com outros discursos que circulavam na época. Assim, foi possível apontar alguns temas relevantes que podem ser debatidos com alunos a partir do trabalho de Nísia, como gênero, segregação ocupacional, empreendedorismo feminino, sub-representação feminina, estereótipos de gênero, liderança feminina, dentre outros. Esses temas podem ser discutidos em disciplinas como Teoria das Organizações ou Teoria Geral da Administração, Gestão de Pessoas, Relações de Trabalho, Empreendedorismo, Responsabilidade Social Empresarial e Gestão Pública. Acredita-se que a experiência literária proporcionada pelos escritos de Nísia pode levar ao acesso de novos conhecimentos, produzindo outras percepções e até mudanças na mentalidade de futuros administradores.

Palavras-Chave: literatura feminista; Nísia Floresta; administração; gênero; mulheres.

\section{Nisia Floresta's feminist literature in management training}

\section{ABSTRACT}

Nísia Floresta is acknowledged as the first Brazilian woman to write about ideals of equality since 1830, and her work composes the 19th century way of thinking. At a time in which most women did not have access to education, this Latin American woman highlighted the female invisibility in the society. The aim of this study is to analyze the use of Nísia's feminist literature in management training. In this sense, it was developed a bibliographic research about books published by her. Moreover, it was taken into account the socio-historical context in which they were produced and their relation to other discourses of this period. Thus, it was possible to point out some meaningful themes that can be argued in class, such as gender, occupational segregation, female entrepreneurship, under-representation of woman, gender stereotypes, women leadership, etc. These themes can be discussed in disciplines like Organization Theory or General Theory of Administration, Human Resource Management, Work Relationship, Entrepreneurship, Corporate Social Responsibility and Public Management. The literary experience provided by Nísia's writings is believed to enable the accessibility to new learnings, other perceptions and even change the future managers' mindset.

Keywords: feminist writings; Nísia Floresta; administration course; gender; women.

Recebido em: 26/11/2020 Revisado em: 06/07/2021 Aprovado em: 16/07/2021

Check for updates

Susane Petinelli Souza (iD,

Universidade Federal do Espírito Santo, Brasil

Doutora em Educação, Universidade

Federal do Espírito Santo

susane.souza@ufes.br 


\section{Introdução}

Administradores são cientistas sociais aplicados e, por essa razão, necessitam de uma formação técnica. Contudo, a formação em Administração não está restrita a aspectos técnicos, tendo em vista que administradores são seres políticos e suas decisões produzem efeitos na sociedade (Fischer, 2003; Ribeiro, 2006; Souza, Waiandt, \& Junquilho, 2015).

Os cursos de Administração podem ser considerados vetores de mudança social, pois contribuem para a formação de mentalidades. Esses cursos têm sido cada vez mais incentivados a incluírem em seus programas de ensino assuntos relacionados a questões como a pobreza, as mudanças climáticas e as desigualdades, assuntos que demandam conhecimento e habilidades multidisciplinares (Dyllick, 2015; Wood, Caldas, \& Souza, 2019).

Os saberes produzidos nos países centrais ainda ocupam posição de destaque no campo da Administração e aqueles estudos que não abordam as teorias e os modelos hegemônicos se tornam marginalizados, determinando, assim, o que é considerado central e o que é periférico (Barros \& Carrieri, 2015). Desse modo, há uma relação centro-margem (Gherardi, Marshall \& Mills, 2003) ou seja, uma relação de subalternidade.

Por falar em subalternidade, permanece a tendência de mulheres e homens se concentrarem em diferentes áreas de atuação na sociedade, enquanto as ocupações tradicionalmente associadas aos homens comumente pagam melhor do que aquelas associadas às mulheres (Miller \& Vagins, 2018). As relações de gênero estão baseadas na desigualdade, ou no chamado patriarcado, em que a estrutura política da humanidade se apresenta como mais arcaica e persistente, estruturando o modo de funcionamento das demais desigualdades de prestígio e poder, como as formas econômicas, políticas, coloniais e raciais de supremacia (Segato \& McGlazer, 2018).

No entanto, assim como Spivak (1994), acredita-se que uma subalterna pode falar e, no presente estudo, uma subalterna da América Latina pode falar. Sobre as mulheres na América Latina, Cusicanqui (2010, p.5) diz que: "No contexto de um desenvolvimento histórico que as hierarquizou, vemos histórias marcadas pela subordinação e exploração da época colonial".

Neste estudo, uma pensadora brasileira do século XIX, mulher do sul global ganha visibilidade. A Literatura examinada para possível contribuição na formação em Administração foi produzida por uma escritora ainda pouco conhecida em seu próprio país, mas importante para o pensamento do século XIX. Trata-se de Nísia Floresta, considerada a primeira brasileira a escrever sobre os ideais de igualdade para as mulheres (Brazil \& Schumaher, 2000; Rosa, 2016; Duarte, 2008, 2016).

Nísia Floresta foi mulher em um país periférico e colonizado e ainda assim seus escritos tiveram repercussão desde 1830. Numa época na qual parte das mulheres praticamente não podia sair de casa e o seu acesso ao conhecimento era quase inexistente, a escritora colocou em evidência a invisibilidade e a tentativa de silenciamento feminino, por meio de sua produção literária. 
Portanto, o uso da Literatura feminista pode chamar a atenção para uma das formas persistentes de desigualdade: aquela baseada em gênero. A partir dessas considerações, o estudo objetiva analisar o potencial uso da Literatura feminista de Nísia Floresta na formação em Administração.

O artigo está organizado do seguinte modo: esta introdução, a educação no século XIX, os procedimentos metodológicos utilizados para o desenvolvimento do estudo e informações sobre a vida da escritora junto a trechos elucidativos de algumas de suas obras. Em seguida, são apontados temas na formação em Administração que podem ser discutidos e refletidos com os alunos a partir da Literatura de Nísia Floresta. Por fim, temos as conclusões.

\section{Educação no século XIX}

Com a chegada da família real em terras brasileiras e com os brasileiros interessados na cultura e nos hábitos franceses (Vasconcelos, 2008), foi sendo ampliada a percepção de que era descabido que praticamente metade da população não tivesse acesso à educação. E ainda que isso ocorresse por interesses distintos, aos poucos, tomou corpo a ideia de que a sociedade precisava de mulheres educadas e habilitadas para contribuírem com o desenvolvimento do Brasil (Duarte, 2008).

Apesar disso, uma característica da sociedade era a delimitação das esferas pública e privada como campos de atuação de homens e mulheres, respectivamente. Durante o século XIX, a vida doméstica sofreu certo enaltecimento, representando uma valorização do papel da mulher no âmbito privado. Com a atuação feminina no âmbito doméstico, o poder da autoridade paterna parecia diminuir, enquanto o poder de autoridade materna aumentava. Porém, ainda cabia ao pai, ao homem, as decisões finais, visto que era o único mantenedor da família (Perrot, 2005; Duarte, 2008; Louro, 2018). Observa-se que no Brasil, somente em 1962, ou seja, no próximo século, foi deliberado que não era mais necessário às mulheres solicitarem a autorização aos maridos para poderem trabalhar.

A primeira lei educacional que autorizou o funcionamento de escolas públicas femininas foi formulada em 1827. Antes disso, as poucas mulheres que conseguiam acessar a educação formal o faziam por meio de conventos e raras escolas particulares nas casas de professoras. A circulação das mulheres pelos espaços públicos ocorria principalmente quando participavam de atividades religiosas, como missas, novenas e procissões. Com isso, o domínio da casa era o seu destino (Louro, 2018; Duarte, 2019). No século XIX, no Brasil, parte das mulheres vivia praticamente enclausurada, sem acesso à educação (Duarte, 2019). As mulheres viviam quase que em isolamento, "longe dos olhos dos estranhos, sendo vistas apenas de esguelha quando iam à igreja" (Costa, 2010, p. 494)

A Lei educacional brasileira determinava que nas escolas do Império, meninas e meninos estudassem separados e com currículos próprios. Enquanto os meninos aprendiam as quatro operações matemáticas, números decimais, frações, proporções e geometria, as meninas aprendiam 
apenas as quatro operações. Isso reforça o sexismo nas relações escolares, visto que destina o desenvolvimento de habilidades intelectuais aos meninos e o de habilidades manuais às meninas (Ferreira \& Schwartz, 2014; Louro, 2018).

A educação feminina era justificada pela maternidade e isso consta na Lei de 1827, que explicitava que as mulheres precisavam de instrução, pois eram as principais responsáveis pela educação de seus filhos (Louro, 2018). Desde o início da educação feminina, esta foi concebida fundamentada em aspectos religiosos e morais, no intuito de preparar as mulheres, desde a infância, para assumirem os papéis de esposa e mãe. Algo bem distante de uma formação intelectualizada, bastando-Ihes o ensino das primeiras letras e o desenvolvimento de habilidades manuais. Para as jovens das elites, havia a possibilidade de prosseguir seus estudos em casa. Mas, a maioria das mulheres, mesmo com a existência de algumas escolas púbicas, raramente continuavam seus estudos (Duarte, 2008).

Para os meninos da elite, o ensino da leitura religiosa e de noções elementares da matemática era complementado pelos conhecimentos de francês e de piano. Para as meninas, era destinada a aprendizagem das habilidades culinárias e de costura e bordado, assim como aquelas relacionadas ao comando de serviçais. Também buscava-se tornar as mulheres uma companhia agradável ao marido. Em sua maioria, as meninas oriundas de camadas mais baixas da sociedade lidavam desde cedo com tarefas rotineiras de cuidado com a casa e com irmãos menores, além do trabalho na roça. Para elas, tais atribuições eram prioritárias em relação a qualquer forma de educação. No que se refere à educação de lusos brasileiros e imigrantes da época, existiam diferenças entre meninos e meninas, também marcando uma divisão baseada em gênero. Já a população de origem africana, ainda escravizada, praticamente não tinha acesso à escolarização, existindo registros de alguns casos da aceitação de crianças negras em escolas ou classes isoladas, apenas no final do século XIX (Louro, 2018).

Portanto, pode-se vislumbrar aspectos históricos para conhecer como a divisão baseada em gênero e a divisão racial se manifestavam naquele tempo. Quanto à educação indígena no século XIX, esta era voltada para um processo civilizatório, o qual tinha por objetivo preparar para o trabalho, enquanto ocorria a tentativa de apagamento de suas línguas e culturas, e suas terras eram ocupadas. Para aquelas meninas indígenas que tinham acesso à educação, a aprendizagem ia desde ensinamentos religiosos cristãos até atividades domésticas. Com isso, para a maioria das pessoas negras e para os indígenas considerados "bravos" a falta de acesso à educação era o único destino, enquanto os indígenas considerados "mansos" eram destinados à educação para o trabalho (Andrade, 2011).

Além da educação formal existia aquela no âmbito doméstico. Tal educação, inspirada nos moldes estrangeiros, era o modo como boa parte das elites brasileiras educavam seus filhos por meio de preceptores. Estes últimos residiam nas casas dos alunos, acompanhando-os nas lições diárias e missas, dentre outros compromissos. Quando se tratava de professores particulares, iam às casas dos alunos com dia e horário marcados. Ressalta-se que a preceptoria era uma atividade majoritariamente exercida por mulheres, sendo uma das poucas 
ocupações permitidas na época, desenvolvida em sua maioria por estrangeiras (Vasconcelos, 2008). Na educação formal, o direito à educação era limitado às rotinas domésticas, bordado, corte e costura (Duarte, 2019); para aquelas que conseguiam algum acesso ao ensino do letramento, as leituras eram limitadas a romances, livros de moral, etiqueta e catecismo (Telles, 2018).

As classes das meninas deveriam ser regidas por senhoras ditas honestas e a partir da lei, ocorreu o estabelecimento das escolas dedicadas ao letramento nas maiores cidades e vilas do Império (Louro, 2018). A exigência do gênero feminino para as professoras dificultava o processo de contratação no magistério, tendo em vista que elas próprias tinham dificuldades de acesso à educação escolar. Ademais, poucas eram as mulheres capacitadas para ensinar (Ferreira \& Schwartz, 2014).

No século XIX também havia uma mudança no tipo de público com acesso à leitura, sendo constituído por mais mulheres, em sua maioria burguesas. Inclusive nas Américas, mesmo envoltas num discurso que buscava naturalizá-las para aquém da cultura e destiná-las à reprodução da espécie e sua nutrição, houve uma profusão de mulheres que começaram a escrever e publicar (Telles, 2018).

Ainda assim, para a maioria das mulheres havia a impossibilidade de se ocupar da escrita, e quando isso era possível, havia a dificuldade de reconhecimento do seu trabalho, ampliando sobremaneira a invisibilidade feminina na história (Perrot, 2005, 2007). Nos anos de 1830 eram raras as mulheres brasileiras educadas e mais raras as escritoras. Para além dos preconceitos no Império, Nísia foi uma das primeiras mulheres a publicar textos em jornais considerados da grande imprensa, com diversas colaborações no formato de poesias, ensaios, contos e crônicas (Duarte, 2008).

Contribuindo para a educação feminina, ela fundou o Colégio Augusto, na cidade do Rio de Janeiro. Em 31 de janeiro de 1838, foi publicado no Jornal do Comércio um anúncio sobre a sua inauguração. Observa-se que a maioria desses estabelecimentos de ensino eram dirigidos por estrangeiros. Dentre a minoria brasileira, encontra-se Nísia (Duarte, 2008, 2010, 2016).

No que se refere a inovações, o estabelecimento de ensino voltado à educação feminina buscava introduzir o estudo de italiano, inglês, francês, latim, história e geografia, além de incentivar à Educação Física e condenar a utilização de espartilho. Também se trabalhava com uma quantidade limitada de alunas em cada classe em prol da qualidade de ensino. Em meio a polêmicas e críticas, o colégio funcionou por cerca de dezoito anos (Brazil \& Schumaher, 2000; Duarte, 2008, 2016).

Nísia criticava a diferença na quantidade de alunos e alunas matriculados na educação primária e secundária, considerando que em 1852 havia 55.000 alunos e somente 8.443 alunas. Enquanto os meninos eram instruídos com o intuito de desenvolver a capacidade intelectual, as mulheres eram educadas para a formação do caráter. A educação feminina no século XIX no Brasil buscava manter a virtude, "em sua conotação sexual e assegurar um comportamento correto perante a sociedade" (Sharpe-Valadares, 1989, p. XI). Por meio do seu estabelecimento de ensino e de suas obras ela denunciou uma sociedade que legitimava as desigualdades (Rosa, 2016). 


\section{Procedimentos Metodológicos}

Os dados que embasaram o apanhado histórico e as obras da escritora foram coletados a partir de fontes bibliográficas (Flick, 2004). O estudo foi qualitativo, com coleta de dados em fontes secundárias, como livros e artigos. A contextualização histórica permitiu o entendimento do modo de funcionamento da educação no século XIX, tornando possível vislumbrar os códigos sociais que buscavam regular as maneiras de fazer e que prescreviam como educar os indivíduos (Foucault, 2008). Dentre as 15 obras da autora, eis aquelas que foram possíveis de serem acessadas:

a. Direito das Mulheres e Injustiça dos Homens - em Duarte (2016).

b. Opúsculo Humanitário - em Floresta (1989 [1853]).

c. Páginas de uma Vida Obscura - em Maia (2017).

d. A Mulher (que compõe o livro Cintilações de uma Alma Brasileira) em Duarte (2010).

e. A Lágrima de um Caeté - em Duarte (1999).

f. Fragmentos de uma obra inédita: notas biográficas - em Augusta (2001 [1878]).

As duas obras em nome de Nísia são Opúsculo Humanitário e Fragmentos de uma Obra Inédita, sendo que na primeira ela está referenciada como Floresta e na última como Augusta - ambas relacionadas com o nome adotado pela autora: Nísia Floresta Brasileira Augusta. Algumas obras estavam hospedadas em sites institucionais e bibliotecas, enquanto outras foram encontradas em sebos e livrarias. Os livros em nome de Duarte (2010, 2016) trazem contidas algumas das obras de Nísia na íntegra. O artigo em nome de Duarte (1999) traz diversos trechos do poema Lágrima de um Caeté. Enquanto o artigo de Maia (2017) contém trechos do folhetim Páginas de uma Vida Obscura.

Neste estudo as obras que veiculam o pensamento de Nísia foram tratadas como construções sociais, ou seja, a produção intelectual de Nísia Floresta se deu a partir das condições sócio-históricas do século XIX, uma época que ainda produzia a invisibilidade feminina. Portanto, cada obra da escritora foi considerada um saber materializado a partir de uma produção sócio-histórica (Foucault, 2008).

A invisibilidade feminina era produzida a partir de várias condições. As mulheres eram menos vistas no espaço público, que era o único espaço que despertava o interesse em relatos e descrições neste período. O silêncio das fontes seria outra condição, visto que o acesso à educação e à escrita era tardio para as mulheres. Outro aspecto é que as mulheres quase não deixavam vestígios escritos. Para que as mulheres fossem registradas na história, eram necessários fontes e documentos, algo escasso até então. Além disso, a própria língua, que usava o gênero masculino no plural, acabava apagando as mulheres da história, assim como as estatísticas, que quase sempre não consideravam o gênero (Perrot, 2007).

Ao longo do tempo, as experiências históricas consideradas dignas de registro começaram a abarcar outras experiências a partir da visibilidade de certas práticas até então silenciadas. Novos sujeitos femininos foram 
incluídos nos discursos históricos, enquanto outras temáticas de estudo emergiram. No Brasil, na década de 1980, por exemplo, amplia-se o leque temático incorporando-se novos agentes sociais, como mulheres, negros, prostitutas e loucas (Rago, 2019). Com esses processos de resgate de memórias, práticas e experiências, que buscam reduzir a invisibilidade das mulheres na história, o século XIX passou a ser considerado como o "século de famílias, de armários e de escrita pessoal, o século XIX é um imenso reservatório. Correspondências, diários, autobiografias foram exumados e analisados como modo de comunicação e expressão" (Perrot, 2005, p. 29).

Desse modo, o potencial uso da Literatura de Nísia Floresta na formação em Administração é analisado, considerando o contexto em que tal Literatura foi produzida e suas relações com outros discursos que também circulavam na época (Alvesson \& Kärreman, 2011).

Que modos de vida estavam sendo criticados por Nísia Floresta? A quais desigualdades ela se referia e até denunciava em seus escritos? Como esses modos de vida e desigualdades ainda reverberam nos dias de hoje na sociedade e nas organizações? Esses e outros aspectos são trazidos à tona ao longo do estudo.

Considerando o conjunto desses aspectos e o fato que Nísia foi uma das exceções de sua época, ao colocar em evidência o seu pensamento, este estudo propõe verificar como a sua Literatura pode contribuir no ensino de temas para administradores e administradoras. No próximo tópico, conta-se um pouco sobre a trajetória e a produção literária da protagonista deste estudo.

\section{Um vislumbre sobre suas obras}

Neste tópico, além de tratar-se um pouco sobre a trajetória de Nísia, sua produção literária é brevemente revisitada, com atenção para alguns trechos de obras, as quais podem suscitar discussões e reflexões profícuas nos cursos de Administração.

Seu nome era Dionísia Gonçalves Pinto, porém, mais tarde, adotou o nome Nísia Floresta Brasileira Augusta, homenageando, ao mesmo tempo, o sítio Floresta onde nasceu, o Brasil e o segundo marido, chamado Augusto. Ela nasceu em 12 de outubro de 1810, no povoado de Papari, no Rio Grande do Norte, vivendo até o ano de 1885. Considera-se que Nísia era escritora, poetisa, uma das primeiras romancistas brasileiras, educadora, tradutora, indianista, abolicionista e feminista (Brazil \& Schumaher, 2000; Duarte, 2008, 2016).

No ano de 1830, Nísia publicou artigos tratando sobre as condições de vida das mulheres no Espelho das Brasileiras, jornal dedicado às mulheres pernambucanas (Sharpe-Valadares, 1989). Em Porto Alegre, em 1834, iniciou a atividade de preceptora de moças e a partir de 1835 publicou artigos utilizando o pseudônimo de Quotidiana Fidedigna no jornal O Campeão da Legalidade e no jornal O Recompilador Federal (Brazil \& Schumaher, 2000). 
Perante a escassez de documentos, o passado histórico das mulheres vem sendo reescrito. Nísia Floresta é considerada a primeira mulher brasileira a publicar e divulgar ideias em prol das mulheres, além de ter publicado suas obras também em outros países. Apesar disso, a escritora foi, por muito tempo, praticamente relegada ao esquecimento (Brazil \& Schumaher, 2000; Rosa, 2016; Duarte, 2008, 2016). Ao dar visibilidade para o pensamento de Nísia, além de temas ligados à história da educação no Império e dos momentos iniciais da participação das mulheres na imprensa brasileira, vem à tona temas ligados ao gênero e à segmentação ou segregação ocupacional na sociedade.

Ao observar-se o conjunto da obra de Nísia Floresta, textos publicados em português, francês, inglês e italiano, é possível perceber a existência de uma complementaridade entre a maioria, e com o propósito de modificar consciências e alterar o quadro ideológico e social (Duarte, 2016).

Depois de algumas matérias em jornais desde 1830, o primeiro livro foi publicado em 1832, o qual trata sobre o direito das mulheres em relação à educação e ao trabalho, mas também sobre as mulheres merecerem respeito pela sociedade (Duarte, 2008).

Intitulado Direito das Mulheres e Injustiça dos Homens, esse livro foi inicialmente tomado como uma tradução livre de Vindication of the Rights of Woman (1792), da feminista inglesa Mary Wollstonecraft. No entanto, sabe-se atualmente que a origem do texto é outra. Acredita-se que outros pensadores, como François Poulain de La Barre e Sophia foram mais utilizados e traduzidos para seu texto. Portanto, seu livro seria proveniente principalmente de Woman Not Inferior to Man (1739), de Mary Wortley Montagu, também inglesa, de pseudônimo Sophia. Contudo, Mary Montagu teria utilizado o livro De l'égalité des deux sexes, de autoria de François Poullain de La Barre, de 1673 (Burke, 1996; Barbosa \& Maia, 2020).

Como argumenta Burke (1996, p.172), o trabalho de Nísia "talvez pudesse ser um daqueles felizes casos lembrados por Borges em que a tradução supera o original", tendo em vista que Nísia fez alterações, acrescentou trechos, e com isso, criou outra escritura, menos radical que as originais. Dizer que era uma tradução de Wollstonecraft, mulher reconhecida na época, talvez tenha sido o modo encontrado para ser ouvida em uma sociedade ainda conservadora.

Além disso, Nísia é reconhecida como a precursora na luta pela igualdade entre homens e mulheres por meio da educação no Brasil, pois não existem outros registros escritos sobre o tema antes de suas publicações (Duarte, 2010, 2016). No entanto, cabe lembrar que:

Para Socorro Trindad, a primeira feminista brasileira foi a índia potiguar Clara Camarão, figura de destaque nas lutas contra os holandeses, durante a primeira metade do século XVII. Nos campos de batalha, ela liderava um grupo de índias no incentivo aos combatentes pró-Portugal para heroicos feitos de armas. Dois séculos adiante, Clara é continuada por outra "guerreira" de sua terra, chamada Dionísia Pinto - nome real de Nísia Floresta (Sharpe-Valadares, 1989, p. 6).

Nísia tinha apenas vinte e dois anos quando publicou em Recife 0 livro Direito das Mulheres e Injustiça dos Homens, que foi quando assumiu definitivamente o nome Nísia Floresta Brasileira Augusta (Brazil \& Schumaher, 2000). Nesse tempo, a autora já havia vivido experiências penosas, em 
tempos conturbados das revoluções que abalaram o Nordeste brasileiro e atingiram sua família, culminando com o assassinato de seu pai português por antilusitanos. Teve um casamento aos treze anos, que acabou quando corajosamente abandonou o seu marido. Viveu com um jovem acadêmico de Olinda numa ligação ilegítima após o primeiro casamento, contraindo o rótulo de adúltera. Além disso, perdeu um filho, morto prematuramente (Burke, 1996; Duarte, 2016). A obra Direito das Mulheres e Injustiça dos Homens foi dedicada às brasileiras e aos acadêmicos brasileiros.

\begin{abstract}
Devós, Patrícias, espero, que longe de conceberdes qualquer sentimento de vaidade em vossos corações com a leitura deste pequeno livro, procureis ilustrar o vosso espírito com a de outros mais interessantes, unindo sempre a este proveitoso exercício a prática da virtude, a fim de que sobressaindo essas qualidades amáveis e naturais ao nosso sexo, que até o presente têm sido abatidas pela desprezível ignorância em que os homens, parece de propósito, têm nos conservado, eles reconheçam que o Céu nos há destinado para merecer na Sociedade uma mais alta consideração. E de vós, mocidade Acadêmica, em quem a Nação tem depositado as mais belas esperanças, que sabereis corresponder à sua expectativa, igualmente espero, que atendendo o estado a que nosso infeliz sexo tem sido injustamente condenado, privado das vantagens de uma boa educação, longe de criticardes a minha temeridade, lamentareis a nossa sorte, pois que até em pequenas empresas não podemos desenvolver nossos talentos naturais (Floresta, conforme citado em Duarte, 2016, p.111).
\end{abstract}

Neste livro é questionado o porquê de os homens procurarem afastar as mulheres das ciências, termo utilizado com o significado de conhecimento ou mesmo de acesso a ele.

Para reconhecer, pois, se as mulheres são menos capazes que os homens para as ciências, é preciso atender qual é o princípio que conduz a este conhecimento; se ele não existe nas mulheres, ou se existe num grau menos perfeito, não se faz necessário mais provas para demonstrar que os homens têm razão. Porém, se ele é perfeito em um como em outro sexo, então deve-se supor os homens invejosos e pode-se dizer, sem temeridade, que a única razão porque nos fecham o caminho às ciências é temerem que nós as levemos a maior perfeição que eles (Floresta, conforme citado em Duarte, 2016, p.132).

Aqui outro trecho emblemático: "Por que a ciência nos é inútil? Porque somos excluídas dos cargos públicos; e por que somos excluídas dos cargos públicos? Porque não temos ciência" (Duarte, 2016, p.136). Nísia menciona, ainda que brevemente, o aspecto da violência contra as mulheres:

Até hoje só se tem tratado superficialmente da diferença dos dois sexos. Todavia os homens arrastados pelo costume, prejuízo e interesse, sempre tiveram muita certeza em decidir a seu favor, porque a posse os colocava em estado de exercer a violência em lugar da justiça [...] (Floresta, conforme citado em Duarte, 2016, p. 119).

No livro aparece também a indagação sobre a possibilidade de as mulheres ocuparem cargos e a desempenharem papéis, então destinados aos homens.

Nada seria tão admirável para eles, que imaginar uma mulher combatendo à frente de um exército, dando leis sobre o trono, advogando causas, administrando justiça em um Tribunal de magistratura, marchando pelas ruas precedida de espadas, lança e outros sinais de autoridade como os Magistrados; ou ensinando Retórica, Medicina, Filosofia, ou Teologia, na qualidade de professora de uma Universidade (Floresta, conforme citado em Duarte, 2016, p. 144). 
Com tais questionamentos sobre o porquê de não haver mulheres ocupando cargos de comando, Nísia inaugura esse debate no país e intenta abalar certas verdades da elite patriarcal da época (Duarte, 2016). Conforme Burke (1996), em seus textos há uma luta por reconhecimento sobre a capacidade das mulheres para desempenhar papéis considerados masculinos, mas também, uma valorização dos papéis de mãe e esposa - 0 que segundo Duarte (1989), caracteriza uma postura ainda conservadora por parte de Nísia. Todavia, com este primeiro livro originado a partir da tradução de outras escritoras, Nísia deixa um registro importante na sociedade patriarcal brasileira (Burke, 1996; Duarte, 2016; Barbosa \& Maia, 2020).

De maio a junho de 1851, no Rio de Janeiro, o jornal O Liberal divulgou alguns artigos seus sob o título A emancipação da mulher, cuja necessidade de uma educação feminina adequada era o tema principal. Em 1852 volta a escrever em jornais, resultando na obra Opúsculo Humanitário (Brazil \& Schumaher, 2000).

Segundo Duarte (2008), a constante presença na imprensa seria um traço da modernidade de Nísia. Como tais jornais compunham a imprensa de grande circulação da época, era necessário algum prestígio para se manter um texto em evidência nos jornais. Nísia também pode ser considerada uma das precursoras na divulgação do pensamento feminista na imprensa.

Enquanto pelo velho e novo mundo vai ressoando o brado emancipação da mulher, nossa débil voz se levanta na capital do Império de Santa Cruz, clamando: educai as mulheres!

Povos do Brasil, que vos dizeis civilizados! Governo, que vos dizeis liberal! Onde está a doação mais importante dessa civilização, desse liberalismo? (Floresta, 1989 [1853], p. 2).

Opúsculo Humanitário foi publicado em 1853, no Rio de Janeiro, com críticas ao sistema de ensino no Brasil imperial. Neste livro, a escritora menciona os equívocos na formação educacional das mulheres (Duarte, 2016).

\begin{abstract}
Temos testemunhado o empenho dos homens pensadores das nações cultas em harmonizar a educação da mulher com o grandioso porvir que se prepara à humanidade. Nada, porém, ou quase nada temos visto fazer-se para remover os obstáculos que retardam os progressos da educação das nossas mulheres, a fim de que elas possam vencer as trevas que lhes obscurecem a inteligência, e conhecer as doçuras infinitas da vida intelectual, a que têm direito as mulheres de uma nação livre e civilizada (Floresta, 1989 [1853], p.44).
\end{abstract}

Ainda no que se refere ao Opúsculo Humanitário, a escritora também coloca em evidência a dificuldade de encontrar registros históricos sobre as mulheres no país: "Não é na história de nossa terra que iremos estudar a situação de nossas mulheres, porque infelizmente os poucos homens que têm escrito apenas esboços delas não as acharam dignas de ocupar algumas páginas de seus livros" (Floresta, 1989 [1853], p.47).

Em várias oportunidades menciona aspectos relacionados à escravização então vigente, ainda que esta seja tema de outra de suas obras - Páginas de uma Vida Obscura, na qual se manifesta sobre o sistema escravocrata (Duarte, 2016). Em Opúsculo Humanitário Nísia apenas fala de algumas consequências nefastas para os escravos, assim como para as meninas que cresciam em meio ao sofrimento destes, num discernimento sobre a 
construção social daquelas que desde a infância presenciam a escravização como sendo a norma vigente.

\begin{abstract}
De um lado os mais rudes tratamentos do senhor para com o escravo, do outro a impotência deste em repelir um jugo anticristão, sancionado pela mais tirânica das leis, e a necessidade do artifício para iludir o senhor e atenuar os sofrimentos da escravidão - tais são os quadros constantemente apresentados na vida doméstica às crianças (Floresta, 1989 [1853], p.97).

Em vez dos jogos de exercício, dos passeios campestres e de pequenos agradáveis trabalhos de uma utilidade real para a infância, acostumam-na em indolente languidez que a faz por vezes contrair males precoces, a depender inteiramente, ainda nas coisas mais fáceis, do auxílio das escravas, sem as quais a mulher brasileira assim habituada nada pode nem sabe fazer (Floresta, 1989 [1853], p.117).
\end{abstract}

Para Nísia, o desenvolvimento social de um país estava atrelado ao nível de emancipação feminina e do lugar que as mulheres ocupavam no arcabouço social. Em seu plano de educação para as mulheres brasileiras, no qual estas assumiriam cargos e posições nas mais variadas esferas, ela se aproxima do pensamento mais progressista, ao mesmo tempo em que permanece limitada por uma formação religiosa conservadora. Ela defende a construção de mais escolas para meninas até equiparação à quantidade daquelas dedicadas aos meninos, demonstrando sua contrariedade com a impossibilidade de acesso feminino à educação de nível secundarista (Duarte, 2008).

Em Páginas de uma Vida Obscura, publicada em 1855, Nísia retrata a trajetória de Domingos, um homem negro escravizado (Brazil \& Schumaher, 2000) e dentre outros temas, trata sobre a destruição de suas famílias, com a separação de mães e filhos. Num primeiro momento a separação familiar surge na vida de um companheiro do protagonista, e depois na vida do próprio Domingos, quando sua mulher é vendida:

\begin{abstract}
Uma santa missão chamou o senhor Domingos ao estrangeiro e longínquo país. Em sua longa ausência a dedicação do sublime negro para com a parte da família, a cujo serviço ficava, não desmentiu jamais, apesar da cruel provança pela qual passou ele vendo vender a mãe de seu filho durante aquela ausência! (Floresta, como citado em Maia, 2017, p.12).
\end{abstract}

A narrativa circulou como folhetim no jornal O Brasil llustrado e conta a história de um homem escravizado, trazido ao Brasil ainda criança. Aborda sua dedicação ao trabalho, enaltecendo suas qualidades e defendendo enfaticamente um tratamento humanitário por parte dos senhores. Por volta de 1870, a escritora passa a defender a abolição. Ela também defendia a liberdade de cultos e a federação das províncias, por meio do sistema de governo republicano (Brazil \& Schumaher, 2000; Rosa, 2016; Duarte, 2016).

Em A Mulher, que compunha o livro Cintilações de uma Alma Brasileira, de 1857, faz denúncias sobre um problema que ocorria na França. Para Duarte (2016, p. 76), nesse texto, é possível verificar um hibridismo de gêneros, característica marcante da maioria de seus trabalhos, oscilando "entre a ficção, o ensaio, a crônica e o texto com propósitos didáticos".

Um dos problemas tratados por ela em $A$ Mulher se referia à morte de muitas crianças que eram enviadas para a casa de amas no campo, mas que acabavam desnutridas e, por vezes, tinham fins trágicos. A história era 
ambientada na França. Em meio ao discurso de que as mães sacrificavam o seu desejo de cuidar dos próprios filhos em favor da saúde deles, uma vez que viveriam retirados da cidade, numa vida mais saudável e com ar puro, o aleitamento materno era considerado um impedimento aos apelos sexuais dos maridos, e visto até como algo inadequado. Tais concepções levavam às mulheres a recusarem o aleitamento (Duarte, 2010). Além disso, também no texto $A$ Mulher, ela demonstrava sua preocupação com a educação não sexista:

\begin{abstract}
O ensinamento da igualdade que deve reinar entre homem e mulher começa neles em relação às próprias irmãs em seus jogos infantis, e em todos aqueles milhares de costumes domésticos, nos quais transparece aquele orgulho excessivo e aquela pretensão do rapazola que tanto vos diverte, e que nada mais é, ó mulheres, senão o germe deste presunçoso egoísmo que vos oprime por toda a vida com prejuízo da própria felicidade deles (Duarte, 2010, p.150).
\end{abstract}

Suas preocupações também são direcionadas à situação indígena ao escrever A Lágrima de um Caeté (1849), poema que trata da degradação dos indígenas brasileiros (Brazil \& Schumaher, 2000). O poema de 712 versos escritos logo após a Revolta Praieira, em Pernambuco, trata da opressão de Portugal e do sofrimento dos indígenas após a colonização. Diferente de outros textos indianistas, ela retrata o indígena derrotado, inconformado com a opressão do branco invasor, e não o indígena herói, como era o costume (Duarte, 2010, 2016).

Segue um trecho do poema: "Ao jugo de tiranos opressores, que em nome do piedoso céu vieram tirar-nos esses bens que o céu nos dera! As esposas, a filha, a paz roubar-nos!... Trazendo d'além-mar as leis, os vícios, nossas leis e costumes postergaram!" (Floresta, como citado em Duarte, 1999, p.164).

Publicou seu último texto na França, intitulado Fragmentos de uma Obra Inédita: Notas Biográficas. Em sua versão brasileira a autora aparece citada como Augusta (2001 [1878]). Este último livro, de 1878, era desconhecido do público, até 1996, quando foi localizado na Bibliothèque Nationale, em Paris. Esse texto é caracterizado pelas saudades da família, pelas memórias em relação ao então falecido irmão em 1875, Joaquim Pinto Brazil. Porém, também contém informações de sua vida no Brasil e na Europa, com acontecimentos históricos, como algumas revoluções no Brasil e a Comuna de Paris (Augusta, 2001 [1878]). Segue trecho que trata de conversa com o seu irmão:

Outrora, tendo comparado todos os sistemas de filosofia e estudado meus filósofos prediletos: Platão, Marco Aurélio, Kant e Descartes, eu Ihe submetia muitas vezes minhas reflexões sobre certos pontos que ele elucidava, segundo sua natureza, dissipando as minhas dúvidas ou fortificando-as por sólidos raciocínios (Augusta, 2001 [1878], p.28).

O pensamento de Nísia foi, em parte, influenciado pelo Positivismo de Auguste Comte em relação ao papel das mulheres na sociedade e na conservação da ordem por meio da suposta superioridade moral e afetiva feminina (Duarte, 2010). Isso decorreu de sua aproximação a Comte, inclusive recebendo-o e frequentando sua casa, e depois se correspondendo com este (Brazil \& Schumaher, 2000). 
Para Burke (1996), sua trajetória intelectual, com o passar do tempo, passou a ser menos radical, mesmo quando infringia convenções sociais. Com isso, vislumbrou-se neste estudo parte ínfima dos textos que compõem a totalidade de sua obra, que ao problematizar a exclusão das mulheres em diferentes espaços, a dificuldade de acesso à educação e ao denunciar a situação na qual se encontravam as mulheres, os negros e os indígenas, produziu material relevante e com potencial uso literário no ensino de Administração.

Nísia mudou-se para a Europa, junto a seus filhos, e residiu em diversos países, vindo a falecer na França no dia 24 de abril de 1885. Em 1948, Papari, sua cidade natal, passou a ser chamada de Nísia Floresta, e em 1954 recebeu seus restos mortais (Brazil \& Schumaher, 2000; Duarte, 2008, 2016).

\section{O que pode a Literatura de Nísia Floresta?}

Considerando a contextualização histórica e, portanto, as condições de produção da Literatura de Nísia, é possível apontar alguns tipos de discurso que circulavam naquele tempo (Alvesson \& Kärreman, 2011): o discurso pedagógico que se referia à educação, no caso, uma educação excludente; o discurso sexista, que fundamentava a segmentação ocupacional na sociedade, produzindo desigualdades desde o cotidiano doméstico até a esfera pública; o discurso religioso que colocava as mulheres como responsáveis pela difusão dos preceitos morais no âmbito familiar, além de reforçar a ideia da maternidade e da devoção à família; o discurso liberal que atendia aos anseios da elite brasileira, ainda baseada no latifúndio e na escravização; e o discurso racista, que procurava subjugar indígenas e negros.

Aliás, as subjetividades de gênero são constituídas nos discursos dominantes que circulam na sociedade e uma posição crítica e resistente torna-se possível a partir desses mesmos discursos (Gherardi et al., 2003). Assim, Nísia produziu um contradiscurso hegemônico (Foucault, 2005, 2008), criticando os modos de vida das mulheres, as restrições impostas e as desigualdades vigentes. A partir de sua Literatura, estudantes de Administração podem ser estimulados a refletir e a debater sobre como tais modos de vida e desigualdades ainda reverberam nos dias de hoje e nas organizações.

O uso das obras de Nísia na formação em Administração, um campo pluriparadigmático, pode incorporar mudanças nas práticas didáticas. Considerando-se a Literatura como um recurso estético, textos de Literatura brasileira podem estimular o envolvimento dos estudantes, tornando mais significativo o processo de aprendizagem, pois recursos estéticos utilizados no ensino podem inspirar, potencializar e até facilitar a aprendizagem (Fischer, Davel, Vergara \& Ghadiri, 2007).

A partir do uso da Literatura é possível estudar e ampliar o conhecimento sobre a Administração, pois o uso da arte literária desperta o interesse pelo sentido das palavras, favorece a compreensão de um texto e o cuidado com o uso de termos e conceitos (Pinheiro, Vieira \& Motta, 2010). Também 
permite descortinar espaços de investigação a partir de um novo olhar sobre o objeto de estudo e pode vir a preparar os estudantes para o exercício da escrita, levando em consideração a estética de uma redação (Baêta, 2007).

Na prática docente é possível abrir espaço para formas mais prazerosas de aprendizagem (Vergara, Davel \& Ghadiri, 2007). Além disso, a Literatura pode compor a estratégia de ensino dos docentes, sendo esta última, um instrumento potente, visto que é um ato intencional, um plano de ação (Fischer et al., 2007).

"Em que pesem as diferenças que os singularizam, os domínios da Literatura e da Gestão apresentam áreas em comum, possibilitando que, a partir de uma, no caso a Literatura, se estude e amplie o conhecimento sobre a outra, a Administração" (Pinheiro et al., 2010, p.647). O uso pedagógico da Literatura também pode contribuir na construção do senso de empatia entre estudantes de Administração, como em estudo que buscava produzir empatia pela natureza e promover um comportamento pró-ambiental (Thexton, Prasad, \& Mills, 2019).

Sobre a possível aplicação de Literatura para estimular debates e reflexões, Fischer et al. (2007) sugerem que as aulas sejam precedidas da leitura da obra pelos alunos, que também podem investigar as personagens literárias, para compreendê-las em seus contextos históricos.

\begin{abstract}
A Literatura permite o acesso à sintonia fina ou ao clima de uma época, ao modo pelo qual as pessoas pensavam o mundo, a si próprias, quais os valores que guiavam seus passos, quais os preconceitos, medos e sonhos. Ela dá a ver sensibilidades, perfis, valores. [...] Para além das disposições legais ou de códigos de etiquetas de uma sociedade, é a Literatura que fornece os indícios para pensar como e por que as pessoas agiam desta e daquela forma (Pesavento, 2005, p.50).
\end{abstract}

No caso das obras de Nísia, a trajetória da própria escritora também pode ser foco de investigação, debate e reflexão, além de poder ser analisada em relação ao contexto histórico no qual viveu. Nesse sentido, Czarniawska (2011) lembra da relevância das histórias de vida, as quais atraem a atenção de críticos literários e cientistas sociais, de modo a enfatizar como os estudos organizacionais contribuíram com o subgênero voltado a histórias de vida profissional.

A Literatura e as artes literárias podem permitir a verificação de iniciativas relacionadas ao processo de gestão, assim como temas pesquisados na área da Administração, como liderança, jogos de poder, conflitos de interesses, ética e valores (Pinheiro et al., 2010).

A partir do presente estudo, são acrescentados temas como gênero, segregação ocupacional, empreendedorismo feminino, sub-representação feminina, estereótipos de gênero, educação sexista, liderança feminina, interseccionalidade, promoção de igualdade e equidade de gênero a partir de políticas públicas e políticas organizacionais. Tais temas podem ser contemplados em disciplinas que versem sobre Teoria das Organizações ou Teoria Geral da Administração, Gestão de Pessoas, Relações de Trabalho, Empreendedorismo, Responsabilidade Social Empresarial, Ética e Gestão Pública, dentre outras.

O tema gênero, com tal terminologia, não existia nos tempos de Nísia. Entretanto, o gênero aparece em suas obras ao colocar em evidência as 
relações entre homens e mulheres, a educação feminina e o modo como as mulheres eram tratadas. Sobre a busca pela igualdade de gênero, Nísia acreditava que tal igualdade seria possível por meio da educação feminina. Uma educação que permitisse o desenvolvimento intelectual e não apenas a aprendizagem de habilidades voltadas para o cotidiano doméstico (Duarte, 2016).

A igualdade de gênero é algo tão relevante, que a Organização das Nações Unidas ([ONU], 2015) colocou a promoção da igualdade de gênero em terceiro lugar entre os oito objetivos do milênio e em quinto lugar nos objetivos da Agenda 2030. De acordo com o Global Gender Gap Index, o Brasil encontra-se na 92. posição, de um total de 153 países, no que se refere à igualdade de gênero (World Economic Forum, 2020). Ao tratar sobre igualdade de gênero no ensino de Administração também é preciso tratar sobre a equidade de gênero, pois ambas não são sinônimos e levam a diferentes resultados.

Os estudantes também podem aprender sobre os princípios para uma educação em gestão responsável a partir do Pacto Global da ONU, que considera a responsabilidade da gestão em relação aos vários grupos que afetam ou são afetados por um empreendimento. Também a importância da diversidade no local de trabalho, a ética nos processos decisórios nos quais existe um dilema, os direitos humanos e naturais, a desigualdade de renda e pobreza, dentre outros (Wall, Mburayi \& Johnson, 2020).

No âmbito das relações de trabalho e das condições de trabalho, podem ser colocados em evidência aspectos como o gap salarial e a subvalorização e desvalorização de determinadas áreas profissionais. Duarte (2016) lembra que no tempo de Nísia, praticamente, somente professoras podiam ensinar às meninas, o que possibilitou uma oportunidade profissional às mulheres, ainda que se tornasse mais uma forma de exploração. Poucas professoras eram habilitadas a lecionar, pois a maioria não conseguia acesso aos estudos, permitindo-lhes apenas ensinar no curso primário, com remuneração inferior à dos colegas homens.

Além do processo de feminização do magistério, aqui também é possível perceber um gap salarial já existente por conta da segmentação ocupacional na sociedade. Segundo Miller e Vagins (2018), quando mais mulheres entram em uma profissão anteriormente dominada por homens, os salários acabam sendo reduzidos, o que evidencia que o trabalho feminino é subvalorizado.

O tipo de trabalho que as mulheres normalmente fazem é desvalorizado, pois o trabalho doméstico é visto como trabalho de apoio e não como um trabalho qualificado. Como resultado, o trabalho desenvolvido por mulheres, por exemplo, enfermeira, secretária e comissária de bordo, é desvalorizado em relação ao trabalho tradicionalmente desenvolvido por homens, como médico, executivo de negócios e piloto de avião (Wienclaw, 2011).

Aspecto ligado ao gênero que também podem ser foco de aprendizagem é a divisão do trabalho com base no gênero, apontando historicamente em como as mulheres ficavam restritas à esfera privada, enquanto aos homens era permitido e incentivado circular pela cidade. Importante lembrar que as mulheres escravizadas circulavam na esfera pública de acordo com a 
vontade de seus senhores, enquanto as mulheres mais pobres de acordo com a vontade de seus maridos.

A divisão do trabalho com base no gênero coloca as mulheres como as responsáveis pelo cuidado de filhos e da casa, em detrimento de suas carreiras (Wienclaw, 2011). A economia neoliberal depende do trabalho feminino. Basta observar o incremento quantitativo de mulheres no mercado de trabalho global, devido ao crescimento da área de serviços e à crescente demanda por trabalhos de cuidado (Oksala, 2011). Daí a resposta feminista ao neoliberalismo não poder limitar-se à questão da redistribuição econômica. O que precisa ser considerado são os próprios limites do mercado e da racionalidade inerente a ele (Oksala, 2013).

A importância do empreendedorismo feminino também pode ser um tema trabalhado com estudantes de Administração, a partir do exemplo de Nísia, pois ela foi uma das primeiras brasileiras a ter um colégio no país, visto que a maioria das instituições de ensino eram dirigidas por estrangeiros (Duarte, 2008, 2010, 2016). Nísia empreendeu num país no qual as mulheres empresárias e trabalhadoras foram mantidas sob tutela dos maridos até 1962. Elas tinham direitos à propriedade, contudo, somente podiam exercer o poder sobre seus bens a partir da autorização de familiares homens ou de algum juiz.

Desde a divulgação da inauguração de seu colégio em jornais, Nísia recebeu duras críticas ao empreendimento, ainda que não se referissem à sua capacidade intelectual ou administrativa, mas às inovações educacionais para as meninas. Outros colégios eram voltados para a aprendizagem de habilidades domésticas, limitando-se a uma instrução precária da língua portuguesa e das operações matemáticas elementares (Duarte, 2016). Desse modo, Nísia também pode ser considerada uma empreendedora no campo educacional do século XIX.

Ainda que as mulheres estejam ocupando posições de destaque em diversas esferas da sociedade, uma das áreas na qual tal processo ainda não é pleno é o mundo dos negócios (Vale, Serafim, \& Teodósio, 2011). Os estudos sobre empreendedorismo e gênero permanecem apontando para uma subordinação das mulheres, visto que estas, muitas vezes, são consideradas diferentes, mais fracas e com dificuldades para atingir o status atribuído ao empresário padrão (Marlow, 2014).

Embora a sub-representação feminina na sociedade seja um reflexo da histórica dificuldade de acesso das mulheres à educação, também pode ser um sinal de culturas institucionais não inclusivas, tampouco voltadas para mudanças sociais e culturais de ampliação da igualdade de gênero (Organização das Nações Unidas para a Educação, a Ciência e a Cultura [UNESCO], 2020).

Em relação à liderança feminina, à ocupação de cargos de liderança e ao processo de ascensão a tais cargos nas organizações, as mulheres ainda passam por mais dificuldades que os homens (Hoobler, Masterson, Nkomo, \& Michel, 2018). Numa perspectiva crítica sobre como a inclusão feminina vem ocorrendo nas organizações, é possível perceber que persistem noções essencialistas de que as mulheres agregam qualidades e características diferentes para o ambiente organizacional, o que pode promover um 
enquadramento comportamental, ou seja, outro modo de exclusão. Com isso, a inclusão de gênero em cargos de liderança e nas organizações depende, dentre outros aspectos, das condições nas quais a inclusão ocorre (Adamson, Kelan, Lewis, Śliwa, \& Rumens, 2021).

Outro tema que pode ser abordado a partir da produção literária de Nísia Floresta são os estereótipos de gênero, pois, para além da capacitação profissional, as mulheres vivenciam sua experiência de trabalho em meio a estereótipos, que operam como barreiras no campo profissional. De acordo com Pomar, Balça, Magalhães e Conde (2019), os estereótipos de gênero demonstram aspectos culturais e de resistência à mudança, atribuindo aos homens traços tradicionalmente relacionados ao campo do trabalho, enquanto as mulheres, traços associados a competências sociais, expressivas e relacionais.

Esses estereótipos moldam percepções, produzindo uma desvalorização da fala e do trabalho realizado pelas mulheres, ao mesmo tempo em que valorizam a fala e o trabalho realizado por homens (Valentine, Trautner, \& Spade, 2019). Para além dos estereótipos de gênero, existem outros tipos de barreiras enfrentadas pelas mulheres em relação ao trabalho, sendo alguns deles conhecidos por meio de metáforas.

Kulik e Rae (2019) tratam do teto de vidro como um dos tipos de barreira que as mulheres experimentam enquanto tentam avançar nas hierarquias organizacionais. Para as autoras, pesquisadores e formuladores de políticas há décadas argumentam que a diversidade de gênero em papéis de liderança pode ser alcançada à medida que as mulheres adquirem mais educação. Entretanto, a relação entre gênero, status profissional e educação é complexa, pois não basta aumentar a educação para que o status social e econômico aumentem (Fox, 2006). Desse modo, percebe-se que não basta o acesso à educação, é preciso mudar mentalidades.

A preocupação com as barreiras que as mulheres vivenciam em relação ao trabalho pode tornar invisível o fato de que a maioria das mulheres nem chega a ter oportunidade de estudar e trabalhar. Isso remete a uma espécie de feminismo chamado pela autora de feminismo civilizatório, que adota e adapta os objetivos de uma missão civilizatória colonial, fornecendo uma política de direitos das mulheres que acaba servindo aos interesses neoliberais (Vergès, 2020). Trata-se ainda de uma modernização da dominação patriarcal que ocorre por meio de práticas disciplinares que subjugam as mulheres pela normalização, não Ihes retirando o exercício de poder, mas que busca estimular determinados tipos de sujeitos (Oksala, 2011).

Importante também tratar da promoção da igualdade de gênero no próprio sistema educacional, pois é na sala de aula que meninos e meninas aprendem a se conformar aos papéis sociais e aos estereótipos de gênero ou a se libertar deles (Wienclaw, 2011). De tal modo, pode-se considerar que o sistema educacional produz comportamentos, mas também resistências (Perrot, 2005). Por isso a promoção de uma educação não sexista em Administração é relevante, pois pode colocar em evidência os estereótipos de gênero na área profissional, apontar preconceitos de gênero nessa área de conhecimento e nas organizações, e colocar em evidência autoras durante os processos de ensino-aprendizagem, tendo em vista que a supressão do 
gênero em citações e referências nas produções científicas e literárias pode levar a uma percepção de que a autoria é sempre masculina.

Sobre a relação de Nísia com a educação feminina, é importante dizer que ela viveu em um tempo com ideias moralistas, de cunho religioso e ideias oriundas do pensamento positivista, o que contribuiu para uma outra demarcação do papel das mulheres, que as colocava como colaboradoras para a ordem social. Nísia propôs uma educação que oportunizasse a inserção das mulheres na sociedade, colaborando com a vida de seus maridos e filhos. Sua proposta educacional não rompia com a lógica patriarcal, apenas a questionava, ainda que buscasse promover o desenvolvimento intelectual feminino (Rosa, 2016; Duarte 2010, 2016).

Segundo Burke (1996), o discurso de Nísia está embasado na promoção da emancipação feminina, por meio da educação, visto que não havia outra forma das mulheres transformarem a sua condição. Ela buscava uma educação feminina que permitisse o acesso ao conhecimento científico, social e artístico.

Outro tema relevante que pode ser trabalhado na formação em Administração é a interseccionalidade de gênero, raça e classe, incluindo ainda outros aspectos como a sexualidade, a idade, a história e o local onde vivem as mulheres, considerando a desigualdade marcada pelo enfoque Norte-Sul (Crenshaw, 1991; Hirata, 2005; Lugones, 2010; Hooks, 2013; Seneviratne, 2018).

Se para Nísia Floresta, uma mulher branca, de pai português, de origem abastada, que circulava em lugares tradicionalmente ocupados por homens, as condições de vida eram caracterizadas pela busca pela igualdade de acesso à educação e a não ser invisibilizada, imagine-se as condições de vida para as mulheres indígenas ou ainda para mulheres que nem ao menos eram livres, como as mulheres negras escravizadas, sem possibilidade de acesso à educação.

Por isso Lugones (2010) também considera a intersecção entre diversos aspectos, de modo a tentar compreender as violências que sofrem as mulheres que se encontram oprimidas por eles, numa imposição colonial sobre o gênero. Aspectos como raça e etnia, idade e classe social se cruzam com o gênero para produzir estereótipos que diferem em significado e funcionamento simbólicos, muitas vezes, produzindo uma desumanização de certos grupos sociais (Valentine et al., 2019).

Inspirando-seem Hooks(2013), o presente estudo pode estimular práticas pedagógicas que promovam o questionamento do sexismo, mas também do racismo, e que permitam outros modos de ensino - como a aprendizagem na área da Administração. Propõe-se um processo educacional que ajude futuras e futuros administradores a perceberem as relações entre a sua experiência cotidiana e as estruturas analíticas de raça, classe e gênero. Com isso, a consideração da interseccionalidade na formação em Administração pode contribuir para a análise de situações sociais e organizacionais e para a promoção de transformações nessas esferas.

Pode-se também tratar de gestão pública, podendo ser ensinado sobre a promoção de políticas públicas, como as políticas educacionais que promovem a igualdade e equidade de gênero e as políticas voltadas para 
a geração de emprego e renda. Em estudo sobre a qualidade do ensino nas políticas educacionais na América Latina, Stromquist (2007) explica que na perspectiva feminista a qualidade educacional não está limitada ao desempenho cognitivo, pois também considera valores e práticas que buscam transformar socialmente as concepções de gênero. A qualidade do ensino inclui saberes que transformam as mentalidades em prol de identidades de gênero menos rígidas, além de estimular uma concepção de cidadania feminina desarticulada da maternidade e do matrimônio, assim como incentiva uma educação sexual e práticas escolares que promovem o respeito e atitudes democráticas.

Ainda podem ser discutidas as políticas organizacionais que buscam promover a redução de barreiras para as mulheres e a ampliação de sua representação em diferentes áreas e níveis organizacionais. E aspectos relacionados à ética nas organizações que, muitas vezes, permanecem reproduzindo desigualdades. Desse modo, procurou-se apontar alguns temas relevantes que podem ser colocados em evidência nos cursos de Administração, mas que não esgotam a potencial utilização do pensamento de Nísia Floresta como Literatura propulsora de reflexões e debates.

Segundo Calás e Smircich (2007), as preocupações feministas apresentam pontos de interseção com os temas organizacionais, pois não dizem respeito somente aos temas sobre as mulheres. Tomar as teorias feministas como lentes conceituais pode produzir um campo de estudos organizacionais que considere as questões de outras pessoas, que além das mulheres, são atingidas pelas organizações por meio de seus processos e discursos. Algo também percebido nas obras de Nísia, que abarcavam uma série de desigualdades que extrapolavam o âmbito feminino. Sua luta pela educação feminina e por mais igualdade entre homens e mulheres acabou tornado visíveis vários tipos de desigualdade.

\section{Conclusões}

Este estudo objetivou analisar o potencial uso da Literatura feminista de Nísia Floresta na formação em Administração. Para isso foi realizada uma pesquisa bibliográfica que permitiu o acesso a algumas de suas obras.

A partir do estabelecimento das condições sócio-históricas de produção do seu pensamento e da leitura de seus escritos, foi possível caracterizar sua produção literária como uma espécie de contradiscurso hegemônico no século XIX (Foucault, 2005, 2008), que permanece relevante ao tratar de temas ligados a desigualdades atreladas ao gênero. Estabelecer quais eram as condições sócio-históricas de sua produção literária também permitiu conhecer um pouco sobre a história educacional do Brasil oitocentista.

Alguns discursos hegemônicos que circulavam (Alvesson \& Kärreman, 2011) no tempo de Nísia foram identificados, como: o discurso pedagógico, o discurso sexista, o discurso religioso, o discurso liberal e o discurso racista, levando à compreensão de que estes criaram as condições que possibilitaram a produção literária e intelectual de Nísia Floresta (Gherardi et al., 2003). 
Seu discurso, além de ser considerado feminista, também pode ser considerado um discurso igualitário, ainda que não equitativo. Também era um discurso abolicionista e indigenista, mas não chegou a ser antirracista. Outro aspecto em relação ao seu discurso é que mesmo defendendo uma educação que permitisse às mulheres assumirem certas posições na sociedade e serem reconhecidas por suas capacidades intelectuais, ela permaneceu atrelada ao discurso religioso e conservador que vinculava as mulheres à maternidade e à família.

O estudo também permitiu identificar temas relevantes na formação contemporânea de Administração. Temas que podem ser debatidos, produzindo processos reflexivos nos alunos. Os temas foram gênero, segregação ocupacional, empreendedorismo feminino, sub-representação feminina, estereótipos de gênero, educação sexista, liderança feminina, interseccionalidade, promoção de igualdade e equidade de gênero a partir de políticas organizacionais e políticas públicas. Tais temas podem ser contemplados em disciplinas que versem sobre Teoria das Organizações ou Teoria Geral da Administração, Gestão de Pessoas, Relações de Trabalho, Empreendedorismo, Responsabilidade Social Empresarial, Ética e Gestão Pública, dentre outras. Não esgotando-se os temas possíveis de serem debatidos a partir da Literatura de Nísia, pretendeu-se chamar a atenção para as formas persistentes de desigualdade no mundo.

Uma limitação do estudo foi o difícil acesso às suas obras, todas publicadas inicialmente nos 1800. Desse modo, o estudo dependeu de publicações mais recentes que deram vida novamente à sua Literatura, ao menos, àquelas mais relevantes.

Nísia Floresta defendia um Brasil livre e sua produção literária também evidenciava uma luta contra o colonialismo. Este estudo possibilitou a recuperação de informações em áreas silenciadas, como vem ocorrendo na antropologia, na sociologia e na história (Spivak, 1994), além de oportunizar a fala de uma mulher da periferia do globo, situada no eixo sul. Portanto, uma subalterna conseguiu falar.

Como sugestão para estudos futuros sugere-se a pesquisa de outras fontes subalternas e silenciadas da Literatura que possam estimular debates e reflexões na formação em Administração, assim como a promoção de pesquisas empíricas que investiguem os resultados da utilização desse tipo de Literatura no processo de ensino-aprendizagem. Outros estudos possíveis seriam sobre os diversos tipos de barreiras para as mulheres, incluindo estudos sobre barreiras de entrada no mercado de trabalho para mulheres com pouca ou nenhuma oportunidade; ou ainda, estudos sobre preconceitos de gênero nas organizações e sobre práticas disciplinares que procuram subjugar, produzindo determinados tipos de comportamentos.

Vozes silenciadas na sociedade podem ter o seu protagonismo invisibilizado pelo esquema dominante heteronormativo, na medida em que os processos de silenciamento produzem um não registro desses pensamentos nos documentos, na história e nos discursos. Nesse ponto também reside a importância de trazer para a formação em Administração uma escritora brasileira oitocentista, conferindo-lhe visibilidade. Alguém 
que por meio de sua Literatura buscava melhores condições de vida e de acesso à educação para as mulheres, rompendo com a invisibilização e o silenciamento femininos no século XIX.

Considerando que a produção de conhecimentos em Administração segue privilegiando aqueles procedentes de homens, além de reproduzir narrativas universais embasadas no esquema homem branco (PetinelliSouza \& Covre, 2021), e todas as dificuldades enfrentadas pelas mulheres nas organizações, a utilização da Literatura de Nísia Floresta pode facilitar o entendimento de como, historicamente, as mulheres permanecem sendo silenciadas e invisibilizadas na sociedade.

Logo, sua Literatura pode contribuir para debates e reflexões voltados para uma formação profissional mais atenta a aspectos sociais, o que pode levar a uma sociedade menos desigual. Acredita-se que a experiência literária possibilitada pela obra de Nísia pode incitar o acesso a novos conhecimentos, outras percepções e até mudanças de mentalidades em futuras e futuros profissionais da Administração.

\section{Referências}

Adamson, M., Kelan, E., Lewis, P., Śliwa, M., \& Rumens, N. (2021). Introduction: Critically interrogating inclusion in organisations. Organization, 28(2), 211227. Recuperado em 16 junho, 2021, de https://journals.sagepub.com/doi/ pdf/10.1177/1350508420973307

Alvesson, M., \& Kärreman, D. (2011). Decolonializing discourse: Critical reflections on organizational discourse analysis. Human relations, 64(9), 1121-1146. Recuperado em 09 agosto, 2020, de https://journals.sagepub.com/doi/10.1177/0018726711408629

Andrade, F. (2011). Instrução moral e ofício doméstico para meninas nas vilas de índios. Cadernos de Pesquisa em Educação, 17(33).

Augusta, N. F. B. (2001). Fragmentos de uma obra inédita: notas biográficas. Brasília: Editora Universidade de Brasília.

Baêta, A. M. (2007). Saramago no ensino e aprendizagem de metodologia de pesquisa. In E. Davel, S. C. Vergara \& D. P. Ghadiri (Orgs.). Administração com arte: experiências vividas de ensino-aprendizagem. (pp. 101-108). São Paulo: Altas.

Barbosa, L. P., \& Maia, V. M. (2020). Nísia Floresta e ainda a controvérsia da tradução de Direitos das mulheres e injustiça dos homens. Revista Estudos Feministas, 28(2), 1-10. Recuperado em 16 setembro, 2020, de https://periodicos.ufsc.br/index.php/ ref/article/view/1806-9584-2020v28n259012

Barros, A., \& Carrieri, A. D. P. (2015). O cotidiano e a história: construindo novos olhares na administração. RAE-Revista de Administração de Empresas, 55(2), 151-161. Recuperado em 09 agosto, 2020, de https://www.scielo.br/scielo. php?pid=S0034-75902015000200151\&script=sci_arttext

Brazil, É. V., \& Schumaher, S. (2000). Dicionário Mulheres do Brasil: de 1500 até a atualidade. Rio de Janeiro: Jorge Zahar Editor.

Burke, M. L. G. P. (1996). Nísia Floresta, O Carapuceiro e outros ensaios de tradução cultural. São Paulo: Editora HUCITEC. 
Calás, M. B., \& Smircich, L. (2007). Do ponto de vista da mulher: abordagens feministas em estudos organizacionais. Handbook de estudos organizacionais, 1, 273-327.

Costa, E. V. (2010). Da Monarquia à República: momentos decisivos. São Paulo: Unesp.

Crenshaw, K. (1991). Mapping the Margins: Intersectionality, Identity Politics, and ViolenceAgainstWomen ofColor. Stanford LawReview, 43(6), 1241-1299. Recuperado em 14 junho, 2021, de https://www.jstor.org/stable/1229039?origin=crossref

Cusicanqui, S. R. (2010). Ch'ixinakax utxiwa: Una reflexión sobre prácticas y discursos descolonizadores. Buenos Aires: Tinta Limón.

Czarniawska, B. (2011). How to Study Gender Inequality in Organizations? In E. Jeanes, D. Knights, \& P. Y. Martin (Eds.). Handbook of gender, work and organization. (pp.81-108). New Jersey: John Wiley \& Sons.

Duarte, C. L. (1989). Nísia Floresta: direitos das mulheres e injustiça dos homens. Editora Cortez: São Paulo.

Duarte, C. L. (1999). Revendo o indianismo brasileiro: A lágrima de um Caeté, de Nísia Floresta. Revista do Centro de Estudos Portugueses, 19(25), 153-177. Recuperado em 09 agosto, 2020, de http://www.periodicos.letras.ufmg.br/index. php/cesp/article/view/6799

Duarte, C. L. (2008). Nísia Floresta e a educação feminina no século XIX. In Y. Lôbo \& L. Faria (Orgs.). Vozes femininas no Império e da República (pp.105-144). Rio de Janeiro: Quartet, FAPERJ.

Duarte, C. L. (2010). Nísia Floresta. Recife: Editora Massangana.

Duarte, C. L. (2016). Direitos das Mulheres e Injustiça dos Homens: Introdução e notas. In E. L. Padilha (Org.). Nísia Floresta uma mulher à frente do seu tempo (pp.95-190). Brasília: Fundação Ulysses Guimarães. Recuperado em 09 agosto, 2020, de https://www.fundacaoulysses.org.br/wp-content/uploads/2016/11/ Nisia-Floresta-completo.pdf

Duarte, C. L. (2019). Feminismo: uma história a ser contada. In E. B. Hollanda (Org.). Pensamento feminista brasileiro: formação e contexto (pp. 25-48). Rio de Janeiro: Bazar do Tempo.

Dyllick, T. (2015). Responsible management education for a sustainable world: the challenges for business schools. Journal of Management Development, 34(1), 16-33. Recuperado em 09 agosto, 2020, de https://www.alexandria.unisg.ch/239159/

Ferreira, D. N. A., \& Schwartz, C. M. (2014). Política, poder e instrução: a educação feminina no método Lancasteriano. Revista Brasileira de História da Educação, (34), 49-72. Recuperado em 15 junho, 2021, de https://periodicos.uem.br/ojs/index.php/ rbhe/article/view/38863

Fischer, T. (2003). Alice através do espelho ou Macunaíma em Campus Papagalli? Mapeando rotas de ensino dos estudos organizacionais no Brasil. Organizações \& Sociedade, 10(28), 47-62. Recuperado em 15 junho, 2021, de https://www.scielo. br/j/osoc/a/Z7vhcvvLQMBdkKtSVYTKXPQ/?lang=pt

Fischer, T., Davel, E., Vergara, S., \& Ghadiri, P. D. (2007). Razão e sensibilidade no ensino de administração: a literatura como recurso estético. Revista de Administração Pública, 41(5), 935-956. Recuperado em 16 setembro, 2020, de https://www.scielo. br/scielo.php?pid=S003476122007000500007\&script=sci_arttext\&tlng=pt 
Flick, U. (2004). Uma introdução à pesquisa qualitativa. Porto Alegre: Bookman.

Floresta, N. (1989). Opúsculo Humanitário. Introdução e notas de Peggy SharpeValadares. São Paulo: Cortez.

Foucault, M. (2005). A ordem do discurso. 12. ed. São Paulo: Edições Loyola.

Foucault, M. (2008). A arqueologia do saber. 7.ed. Rio de Janeiro: Forense Universitária.

Fox, M. F. (2006). Gender, hierarchy, and science. In B. Risman, C. Froyum \& W. J. Scarborough (Eds.). Handbook of the Sociology of Gender (pp.441-457). Boston: Springer.

Gherardi, S., Marshall, J., \& Mills, A. J. (2003). Theorizing gender and organizing. In R. Westwood \& S. Clegg (Eds.). Debating organizations: Point-counterpoint in organization studies (pp.325-338). New Jersey: Blackwell Publishing Ltd.

Hirata, H. (2005). Globalização, trabalho e gênero. Revista de Políticas Públicas, 9(1), 111-128. Recuperado em 14 junho, 2021, de http://www.periodicoseletronicos. ufma.br/index.php/rppublica/article/view/3770

Hoobler, J. M., Masterson, C. R., Nkomo, S. M., \& Michel, E. J. (2018). The business case for women leaders: Meta-analysis, research critique, and path forward. Journal of Management, 44(6), 2473-2499. Recuperado em 15 junho, 2021, de https://journals.sagepub.com/doi/abs/10.1177/0149206316628643

Hooks, B. (2013). Ensinando a transgredir: a educação como prática da liberdade. São Paulo: WMF Martins Fontes.

Kulik, C. T., \& Rae, B. (2019). The Glass Ceiling in Organizations. In Oxford Research Encyclopedia of Business and Management. Recuperado em 05 agosto, 2020, de https://oxfordre.com/business/view/10.1093/acrefore/9780190224851.001.0001/ acrefore-9780190224851-e-41

Louro, G. L. (2018). Mulheres na sala de aula. In M. B. Del Priore (Org.) História das mulheres no Brasil (pp.443-481). São Paulo: Editora Contexto.

Lugones, M. (2010). Toward a decolonial feminism. Hypatia, 25(4), 742-759. Recuperado em 05 agosto, 2020, de https://onlinelibrary.wiley.com/doi/abs/10.1111/ j.1527-2001.2010.01137.x

Maia, L. D. S. (2017). Páginas da escravidão: raça e gênero nas representações de cativos brasileiros na imprensa e na literatura oitocentista. Revista de História, (176), 1-33. Recuperado em 05 agosto, 2020, de https://www.scielo.br/j/rh/a/WvKcHgKT vPFmGTFhqwcYYBw/?lang=pt\&format=pdf

Marlow, S. (2014). Exploring future research agendas in the field of gender and entrepreneurship. International Journal of Gender and Entrepreneurship (pp.102-120). Recuperado em 15 junho, 2021, de https://www.emerald.com/ insight/content/doi/10.1108/IJGE-01-2013-0003/full/html

Miller, K. \& Vagins, D. J. (2018). The simple truth about the gender pay gap. In American Association of University Women. Recuperado em 16 setembro, 2020, de https://www.aauw.org/app/uploads/2020/02/AAUW-2018-SimpleTruth-nsa.pdf

Oksala, J. (2011). The neoliberal subject of feminism. Journal of the British Society for Phenomenology, 42(1), 104-120. Recuperado em 16 setembro, 2020, de https://www.tandfonline.com/doi/abs/10.1080/00071773.2011.11006733?journal Code $=$ rbspO 
Oksala, J. (2013). Feminism and neoliberal governamentality. Foucault Studies, (16), 32-53. Recuperado em 16 setembro, 2020, de https://rauli.cbs.dk/index.php/ foucault-studies/article/view/4116

Perrot, M. (2005). As mulheres ou os silêncios da história. São Paulo: EDUSC.

Perrot, M. (2007). Minha história das mulheres. São Paulo: Contexto.

Pesavento, S. J. (2005). História \& História Cultural. Belo Horizonte: Autêntica.

Petinelli-Souza, S. \& Covre, I. G. (2021). Mulheres na teoria geral da administração: por uma educação não sexista. Revista Em Pauta: teoria social e realidade contemporânea, 19(47), 217-231. Recuperado em 15 junho, 2021, de https://www.e-publicacoes.uerj.br/index.php/revistaempauta/article/view/56085

Pinheiro, I. A., Vieira, L. J. M., \& Motta, P. C. D. (2010). Construindo pontes entre saberes: da literatura à gestão. Organizações \& Sociedade, 17(55), 641-664. Recuperado em 09 agosto, 2020, de https://www.scielo.br/scielo.php?pid= S1984-92302010000400004\&script=sci_arttext

Pomar, C. J. B., Balça, Â. M. P., Magalhães, O. M. S., \& Conde, A. F. (2019). Contributos e desafios da formação contínua de docentes para a construção da igualdade de género e cidadania. Cuestiones de género: de la igualdad y la diferencia, (14), 403-422. Recuperado em 09 agosto, 2020, de http://revpubli.unileon.es/index. php/cuestionesdegenero/article/view/5816

Rago, M. (2019). Epistemologia feminista, gênero e história. In E. B. Hollanda (Org.). Pensamento feminista brasileiro: formação e contexto (pp.371-188). Rio de Janeiro: Bazar do Tempo.

Ribeiro, J. U. (2006). Política e administração. Organizações \& Sociedade, 13(37), 167-198. Recuperado em 09 agosto, 2020, de https://periodicos.ufba.br/index.php/ revistaoes/article/viewFile/10854/7800

Rosa, G. R. da (2016). (Re)pensando o feminismo de Nísia Floresta e a sua contribuição para a história e literatura brasileira. Cadernos Literários, 24(1), 81-90. Recuperado em 09 agosto, 2020, de https://periodicos.furg.br/cadliter/article/view/9222

Segato, R. L., \& McGlazer, R. (2018). A manifesto in four themes. Critical Times, 1(1), 198-211. Recuperado em 14 junho, 2021, de https://read.dukeupress.edu/criticaltimes/article/1/1/198/139314/A-Manifesto-in-Four-Themes.

Seneviratne, P. (2018). MarxistFeminism Meets Postcolonial Feminism in Organizational Theorizing: Issues, Implications and Responses. Journal of International Women's Studies, 19(2), 186-196. Recuperado em 09 setembro, 2020, de https://vc.bridgew. edu/jiws/vol19/iss2/12/

Sharpe-Valadares, P. (1989). Introdução e notas. Opúsculo Humanitário. São Paulo: Cortez.

Souza, S. P., Waiandt, C., \& Silva Junquilho, G. (2015). Administração: Embates da Profissão e a Produção de um Campo de Trabalho. Revista Administração em Diálogo-RAD, 17(3), 129-148. Recuperado em 05 agosto, 2020, de https://revistas. pucsp.br/rad/article/view/19317

Spivak, G. C. (1994). Can the Subaltern Speak? In P. Williams \& L. Chrisman (Eds.). Colonial Discourse and Post-Colonial Theory: A Reader. Hemel Hempstead: Harvester Wheatsheaf. 
Stromquist, N. P. (2007). Qualidade de ensino e gênero nas políticas educacionais contemporâneas na América Latina. Educação e Pesquisa, 33(1), 13-25. Recuperado em 05 agosto, 2020, de https://www.scielo.br/scielo.php?pid= S1517-97022007000100002\&script=sci_abstract\&tlng=es

Telles, N. (2018). Escritoras, escritas, escrituras. In M. B. Del Priore (Org.). História das mulheres no Brasil (pp.402-442). São Paulo: Editora Contexto.

Thexton, T., Prasad, A., \& Mills, J. A. (2019). Introduction: Learning empathy through literature. Culture and Organization, 25(2), 83-90. Recuperado em 14 junho, 2021, de https://www.tandfonline.com/doi/full/10.1080/14759551.2019.1569339.

United Nations Educational, Scientific and Cultural Organization (2020). Global Education Monitoring Report - Gender Report: A new generation: 25 years of efforts for gender equality in education. Paris, UNESCO. Recuperado em 20 outubro, 2020, de https://en.unesco.org/gem-report/.

United Nations Organization (2015). Transforming our world: the 2030 agenda for sustainable development. Recuperado em 16 setembro, 2020, de https://sdgs. un.org/.

Vale, G. M. V., Serafim, A. C. F., \& Teodósio, A. D. S. D. S. (2011). Gênero, imersão e empreendedorismo: sexo frágil, laços fortes? Revista de Administração Contemporânea, 15(4), 631-649. Recuperado em 09 agosto, 2020, de https://www.scielo.br/scielo.php?pid=S1415-65552011000400005\&script=sci_arttext.

Valentine, C. G., Trautner, M. N., \& Spade, J. Z. (2019). The kaleidoscope of gender: Prisms, patterns, and possibilities. New York: Sage Publications.

Vasconcelos, M. C. C. (2008). Vozes femininas nos Oitocentos: o papel das preceptoras nas casas brasileiras. In Y. Lôbo \& L. Faria (Orgs). Vozes femininas no Império e da República (pp.19-46). Rio de Janeiro: Quarte: FAPERJ.

Vergara, S. C.; Davel, E. \& Ghadiri, D. P. (2007). Concluindo: 287-290. Arte no ensino da administração e administração com arte. In E. Davel, S. C. Vergara \& D. P. Ghadiri (Orgs.). Administração com arte: experiências vividas de ensino-aprendizagem. São Paulo: Altas.

Vergès, F. (2020). Um feminismo decolonial. São Paulo: Ubu Editora.

Wall, T., Mburayi, L., \& Johnson, N. (2020). Principles of Responsible Management Education. Quality Education, 640-653. Recuperado em 20 outubro, 2020, de https://link.springer.com/referenceworkentry/10.1007\%2F978-3-319-95870-5_52.

Wienclaw. R. (2011). Sociology Reference Guide Gender Roles \& Equality. New Jersey: Salem Press.

Wood J. R., T., Caldas, M. P., \& Souza, R. J. (2019). Um novo modelo para as escolas de administração. GV Executivo, 18(5), 12-16. Recuperado em 09 agosto, 2020, de http://bibliotecadigital.fgv.br/ojs/index.php/gvexecutivo/article/view/80369

World Economic Forum (2020). Global-gender-gap-report-2020. Recuperado em 20 outubro, 2020, de http://reports.weforum.org/global-gender-gap-report-2020/ dataexplorer 